Original Research Paper

\title{
Paving the Way for Warehouse Centralization in Healthcare: A Preliminary Assessment Approach
}

\author{
Anna Corinna Cagliano, Sabrina Grimaldi and Carlo Rafele \\ Department of Management and Production Engineering, Politecnico di Torino, Italy
}

\section{Article history}

Received: 21-04-2016

Revised: 29-04-2016

Accepted: 02-05-2016

Corresponding Author: Anna Corinna Cagliano Department of Management and Production Engineering, Politecnico di Torino, Italy Email: anna.cagliano@polito.it

\begin{abstract}
Centralized logistics management is currently one interesting option for healthcare systems facing an increasing need to improve responsiveness and service quality while reducing costs. This work focuses on one aspect of centralized logistics, namely warehouse centralization and proposes a preliminary approach to assess material management in healthcare institutions as a first step towards decisions about the implementation of such a strategy. A list of variables and relationships between them characterizing warehouse material management are identified based on a literature review and knowledge of real logistics processes. Statistical analysis is then applied to assess the existence of such relationships in a set of healthcare organizations in order to understand the management commonalities that can stimulate warehouse centralization as well as the criticalities that could potentially hinder it. The approach is tested in a healthcare logistics system in Northern Italy. The results proved the ability of the methodology to identify the relevant issues the involved institutions need to work on when undertaking warehouse centralization strategies. The case warehouses revealed a good degree of commonalities in their management practices although three critical aspects were identified, namely a limited efficiency in human resource allocation, a high fragmentation of stock product demand and a relevant number of stock products with low annual demand. This work provides a methodology to increase material managers' awareness about the factors enabling successful centralized inventory strategies in the healthcare sector.
\end{abstract}

Keywords: Healthcare, Logistics, Warehouse, Centralization, Statistical Analysis

\section{Introduction}

Healthcare (HC) systems currently need to improve the efficiency of both clinical and non-clinical processes in order to better control costs and enhance the quality of the delivered services (Bendavid and Boeck, 2011). Together with information technology (Alrawabdeh et al., 2015; Suresh and Alli, 2012), logistics and Supply Chain Management (SCM) are key levers to achieve this goal.

Logistics plays a significant role as a back-end for provision of efficient and effective $\mathrm{HC}$ services and is one main source of expenditure. As a matter of fact, on average about $30-40 \%$ of a hospital budget is spent on logistics activities, mostly related to material flows (Scheller and Smeltzer, 2006), being the second largest expense for hospitals after total labor costs (Aronsson et al., 2011). However, SCM education is still missing in hospitals and many of the existing material management problems actually come from either applying outdated Supply Chain (SC) strategies, or not adopting them at all, or from a scarce integration among the different SC partners (Böhme et al., 2013).

There are several literature contributions that since the beginning of the Nineties have timidly started addressing issues related to logistics and SCM in the HC sector, but there is still little academic research on $\mathrm{HC}$ SCM. In particular, there are few studies that focus on all the significant system elements and relationships between them (Bhakoo et al., 2012; Rich and Piercy, 2013). Among the relevant literature, a number of works (Nicholson et al., 2004; Pan and Pokharel, 2007) have addressed the benefits and limitations of logistics outsourcing in $\mathrm{HC}$ organizations as a way of achieving efficiency by focusing internal resources on core processes (Brunetta et al., 2014). Another topic well 
debated in literature is inventory management due to its relevance in HC logistics dealing hospitals with large amounts of a great variety of products and carrying inventory costs ranging from 10 to $18 \%$ of the net revenue (De Vries, 2011). Within such a research stream, collaborative arrangements, cross-docking and vendor management inventory are discussed (Bhakoo et al., 2012; Marquès et al., 2010; Su et al., 2011). A further aspect that is gaining momentum in HC SCM is warehouse centralization. While there is a considerable body of literature on the topic in the manufacturing sector, only isolated applications to $\mathrm{HC}$ systems and analyses of the related performance are currently available (Ferretti et al., 2014; Lega et al., 2013; Wu et al., 2015). Studies in both the manufacturing and the HC sectors are mainly focused on either the structure of centralized logistics networks or the associated effects, while there is a lack of methods to assess the degree of commonalities between the material management strategies adopted by the involved organizations that can make warehouse centralization initiatives successful.

With the aim of contributing to bridge such a research gap, the present work develops a structured approach to quantitatively study the common features in managing materials by a set of $\mathrm{HC}$ organizations that aim to implement centralized inventory management. Statistical analysis is applied by focusing on the relationships among the major logistics variables. The results of the first application of the methodology prove its ability to provide preliminary insights about the crucial aspects to consider when designing centralized warehouse strategies.

The paper is organized as follows. The next section introduces the warehouse centralization issue and the associated literature. The Materials and Methods section presents the approach and then the Results section details the outcomes of its application to a number of institutions forming a regional $\mathrm{HC}$ logistics system. The Discussion section explains benefits, implications, limitations of the approach as well as future research directions. Finally, conclusions are conveyed.

\section{Warehouse Centralization}

Warehouse centralization is a way of achieving inventory pooling that has been widely debated in manufacturing literature since the late Seventies (Eppen, 1979), especially with reference to some industries such as spare parts, food and retail. Several research streams can be found about the number and the location of central warehouses as well as the associated demand assignments in order to optimize holding and distribution costs (Lee and Jeong, 2009), the number of companies that should take part in a centralization initiative (Wang and Yue, 2015), the drivers for warehouse centralization (Pedersen et al., 2012), the potential of warehouse centralization to mitigate supply and demand risks (Schmitt et al., 2015), the impacts of allocation rules on inventory and service levels (Alptekinoğlu et al., 2012; Çelebi, 2015; Wanke and Saliby, 2009) and the allocation of costs and benefits among the parties involved in warehouse centralization (Karsten and Basten, 2014; Wong et al., 2007).

Coming to the HC sector, there is still little literature on warehouse centralization (Wu et al., 2015). Among the available contributions, Lega et al. (2013) propose a framework for assessing the performance of a regional network of $\mathrm{HC}$ institutions implementing this logistics model. Their dashboard includes three macrodimensions, namely operational costs, financial benefits and organizational benefits. Ferretti et al. (2014) identify the impacts, in terms of efficiency and costeffectiveness, of logistics improvements in a hospital pharmacy with particular attention to warehouse centralization. Such a strategy brings many advantages because it stimulates different $\mathrm{HC}$ organizational units to use the same products, thus leading to a standardization of the associated logistics procedures, with undeniable savings due to economies of scale and scope.

Warehouse centralization is one key element of centralized SCs. Thus, taking a broader perspective, Battini et al. (2013) address the development of centralized HC supply networks and apply the System Dynamics (SD) methodology to understand the benefits of logistics economies of scale as well as the existing risk of failure under uncertainty. Azzi et al. (2013) apply the same methodology to support the decision of whether selfmanaging or outsourcing logistics operations in centralized $\mathrm{HC}$ networks and find that logistics outsourcing is often the most economic choice. Finally, Wu et al. (2015) adopt the SD approach to investigate a drug SC in China, including patients, hospitals, distributors and manufacturers and to propose warehouse centralization in order to reduce the probability of shortage as well as the amount of money associated with stock.

As it can be noted, most of the works about warehouse centralization, not only in the $\mathrm{HC}$ but also in the manufacturing sector, focus on either the structure of the associated logistics network or its performance and effects and there is a lack of methodologies that assess the degree of commonalities between logistics approaches adopted by different organizations prior to the implementation of any centralized model. Nevertheless, a logistics management centralization policy faces a smooth implementation only when the involved institutions already apply some common sound management practices. As a matter of fact, differences in the way logistics processes are managed might later lead to integration problems. Therefore, it is important before undertaking warehouse centralization to analyze the common characteristics in the material management processes of the focus institutions and to understand the areas requiring attention. 


\section{Materials and Methods}

The basic units of analysis of the proposed approach are the main warehouses for inbound products serving hospitals and other $\mathrm{HC}$ institutions since they are the nodes of a logistics network in charge of planning and managing the connections between suppliers and customers (Faber et al., 2013). The methodology unfolds according to the following six steps that were defined by a working group composed by the authors and the warehouse managers of a set of $\mathrm{HC}$ organizations in Northern Italy that also took part in the first application of the approach:

- Defining the focus warehouses and understanding their operational processes

- Identifying the variables characterizing the most important aspects of warehouse material management by taking into account the nature of products, the variability of demand and the different delivery methods. The variable selection is performed by integrating the understanding of the warehouse processes developed in step 1 with literature

- Identifying the main relationships among the selected variables, again according to the understanding of the warehouse processes at issue and literature

- Collecting quantitative data about the identified variables by means of questionnaires and/or interviews to hospital material managers in order to build the associated dataset

- Applying statistical analysis to investigate whether the previously defined relationships among variables are satisfied by the management practices adopted by the studied warehouses. The statistical significance of each relationship will prove whether it is true for at least the majority of the warehouses, thus showing a commonality in their logistics policies. This approach provides a static analysis, a kind of a picture of the current situation and does not investigate how the relationships might change overtime

- Interpreting results

In order to clarify the approach and make it reproducible, the description of each step is carried out by taking as an example the test application to a $\mathrm{HC}$ logistics system.

Step 1: Defining Warehouses and Analyzing their Processes

This first application of the proposed approach involved 80 warehouses part of the same regional $\mathrm{HC}$ system. In recent years such $\mathrm{HC}$ system has started considering centralized logistics policies as a means to reduce the high costs without compromising patient service levels. The warehouses belong to $19 \mathrm{HC}$ organizations, 13 local $\mathrm{HC}$ agencies and 6 hospital institutions and serve a total of 56 public hospitals and a multitude of clinics and other $\mathrm{HC}$ facilities in a geographical area of about 25,400 square meters with approximately 4,415,000 inhabitants. The warehouses buy and deliver drugs, medical devices and consumable products that are managed as stock, direct delivery and consignment stock items (Scheller and Smeltzer, 2006). Stock products are delivered to their points of use (e.g., the hospital wards) from the warehouse where an appropriate amount is stored. They include the most frequently and commonly used items: Consumable products, most of drugs and part of medical devices, especially the less specific ones. Consignment stock products, usually represented by very expensive and specific medical devices, are legally owned by the suppliers but held by the $\mathrm{HC}$ institution. The ownership of such products is passed to the latter only when they are used. The warehouse takes care of purchasing these items whenever a certain amount is consumed but they usually do not pass through the warehouse, being shipped directly to the points of use. Finally, direct delivery products are ordered by the warehouse but are not stored in it. In fact, their suppliers may deliver them either to the points of use or to the warehouse but in this second case the warehouse acts just as a transit point. They are constituted by not frequently or commonly used products or by high value items, especially medical devices and drugs. Unlike consignment stock, their ownership passes to the $\mathrm{HC}$ institution when they are delivered to it, as it happens for stock products.

The working group composed of the authors and the warehouse managers from the involved organizations studied in detail the operational processes of each warehouse by direct observations of workflows, analysis of documentation and interviews to managers and employees. The collected pieces of information were organized in cross-functional flow charts (Damelio, 2011) in order to easily understand the activities, the logical connections among them and their order of execution. Flow charts representing both the involved activities and the associated informational flows were developed.

\section{Step 2: Defining Warehouse Variables}

Based on the outcomes of the first step of the approach, the working group reviewed mainstream literature about logistics management in both the $\mathrm{HC}$ and the manufacturing sectors and identified a set of variables that best represent the main aspects of the studied inbound and outbound warehouse processes (Table 1). When necessary, each variable has been decomposed into a number of subvariables according to the different product categories or delivery methods. The reference works that proved to be useful to perform such a task are reported in Table 2. In addition, the definition of the variables was supported by looking at the performance indicators suggested by the SCOR Model (SCC, 2012), being it a widely accepted and 
comprehensive SC reference framework that can be adapted also to non-manufacturing industries. In particular, the indicators related to warehouse logistics processes were considered and for each metric pertinent to the case study a logistics variable with a similar meaning was derived. For

Table 1. Selected warehouse variables

\begin{tabular}{ll}
\hline Variable name Sub-variable name & $\begin{array}{l}\text { Scor } \\
\text { process }\end{array}$ \\
\hline 1 WH Area & Make
\end{tabular}

2 Total \# of employees

3 Total \# SKUs

4 Total \# in order lines

3.1 \# Stock SKUs

3.2 \# Direct delivery SKUs

3.3 \# Consignment stock SKUs

4.1 \# Stock in order lines

4.2 \# Direct delivery in order lines

5 Total inventory level

5.1 Drug inventory level Source, Deliver

5.2 Medical device inventory level

6 Inventory turnover

5.3 Consumable inventory level

\section{Days of Supply}

8 Total \# out order lines $8.1 \quad$ \# Stock out order lines

8.2 \# Direct delivery out order lines

9 Total delivered quantity 9.1 Drug delivered quantity

10 Total stock delivered quantity

9.2 Medical device delivered quantity

9.3 Consumable delivered quantity

10.1 Stock drug delivered quantity

10.2 Stock medical device delivered quantity

10.3 Stock consumable delivered quantity

11 Total direct delivered quantity

11.1 Direct drug delivered quantity

11.2 Direct medical device delivered quantity

12 Total consignment stock delivered quantity

12.1 Consignment stock medical device delivered quantity example, the indicator Finished Goods Inventory Days of Supply suggested the variables about the inventory levels of the different kinds of products and the indicator Current Delivery Volume supported the definition of the variables representing the quantities delivered from a warehouse.

\section{Definition}

Total warehouse floor area

Make Number of people involved in the logistics activities of a warehouse. It includes both direct and indirect labor as well as permanent and temporary employees and it is calculated as Full Time Equivalent (FTE) units

Make Total number of SKUs managed in a warehouse

Source Total number of incoming order lines over a given time period, for instance one year

Plan, Average inventory level of stocked drug products, medical devices and consumable products over a given time period, for instance one year. It can be calculated as either the number of units or the associated economic value

Plan Number of times products stocked in the warehouse cycles or turns over a given time period, for instance one year. It can be calculated based on either the number of units of products or the associated economic value

Plan Number of days the demand is covered by the quantity currently stocked in the warehouse. It can be calculated based on either the number of units of products or the associated economic value

Deliver Total number of outgoing order lines over a given time period, for instance one year

Deliver Total amount of products that have been delivered from a warehouse in a given time period. It includes drugs, medical devices and consumable products, both stock and direct delivery items passing through the warehouse. In order to completely represent the overall activities that are managed by the warehouse, this variable also includes consignment stock products, being them not delivered but ordered by the warehouse. It can be calculated as either the number of units or the associated economic value

Deliver Total amount of drugs, medical devices and consumable products stocked in a warehouse that are delivered in a given time period. It can be calculated as either the number of units or the associated economic value

Deliver Total amount of direct delivery products (drugs and medical devices) that are sent by a warehouse to their points of use in a given time period. It can be calculated as either the number of units or the associated economic value. This variable does not include the consumable products because they are usually managed as stock products.

Deliver Total amount of consignment stock products purchased by a warehouse that are delivered to their points of use in a given time period. It can be calculated as either the number of units or the corresponding economic value. The associated sub-variable only includes medical devices since the quantity of drugs and consumable products managed as consignment stock is usually minimal.

Make, Total cost of the personnel involved in the logistics activities of a warehouse. It can be calculated over one year

Make, Total cost for warehouse space and management, without including the cost of personnel. It can be calculated over one year.
13 Total personnel costs

Deliver

Deliver 
Table 1 shows for each variable the processes associated with the corresponding indicator in the SCOR Model. Most of the variables are related to Plan, Source and Deliver, three key processes when dealing with warehouses. Although important in HC logistics systems, the Return process was not considered because it involves a limited flow of products and thus it is not crucial in centralized logistics management decisions in order to achieve efficiency.

\section{Step 3: Defining Relationships among Warehouse Variables}

In a warehouse the variables introduced in Table 1 are connected by specific cause and effect relationships. The existence of such relationships in the warehouses analyzed with the present approach will show a commonality of managerial methods that can facilitate the future implementation of centralized logistics strategies. Table 2 presents those relationships involving variables and sub-variables detailed in Table 1 the working group identified as the most representative of the operational processes carried out in the analyzed warehouses. Such relationships have been selected again based on a literature review in the fields of logistics and $\mathrm{SCM}$ in the $\mathrm{HC}$ and manufacturing industries. Being these relationships the starting point for the subsequent statistical analysis aimed at investigating causes and effects among warehouse variables, for each of them the dependent variable as well as the associated independent variables is identified.

Table 2. Relationships among variables

\begin{tabular}{|c|c|c|c|c|}
\hline \multicolumn{2}{|c|}{ Dependent variable (Effect) } & \multicolumn{2}{|c|}{ Independent variable (Cause) } & \multirow{2}{*}{$\begin{array}{l}\text { References } \\
\text { Brewer } \text { et al. (2008) }\end{array}$} \\
\hline \multirow{5}{*}{$\frac{\text { Depend }}{9}$} & \multirow[t]{5}{*}{ Total delivered quantity } & 3 & Total \# SKUs & \\
\hline & & 3.3 & \# Consignment stock SKUs & Silver et al. (1998) \\
\hline & & 10 & Total stock delivered quantity & Scheller and Smeltzer (2006) \\
\hline & & 11 & Total direct delivered quantity & \\
\hline & & 12 & Total consignment stock delivered quantity & \multirow{4}{*}{ Brewer et al. (2008; } \\
\hline 10 & Total stock delivered quantity & 3.1 & $\begin{array}{l}\text { \# Stock SKUs } \\
\text { Silver et al., 1998) }\end{array}$ & \\
\hline 11 & Total direct delivered quantity & 3.2 & \# Direct Delivery SKUs & \\
\hline 12 & $\begin{array}{l}\text { Total consignment } \\
\text { stock delivered quantity }\end{array}$ & 12.1 & $\begin{array}{l}\text { Consignment stock medical } \\
\text { device delivered quantity }\end{array}$ & \\
\hline \multirow[t]{3}{*}{1} & \multirow[t]{3}{*}{ WH Area } & 5 & Total inventory level & Gu et al. (2010) \\
\hline & & 3.1 & $\begin{array}{l}\text { \# Stock SKUs } \\
\text { Frazelle, 2002) }\end{array}$ & Faber et al. (2013; \\
\hline & & 3 & Total \# SKUs & \\
\hline 5 & Total inventory level & 10 & Total stock delivered quantity & Silver et al. (1998) \\
\hline 5.1 & Drug inventory level & 10.1 & Stock drug delivered quantity & \\
\hline 5.2 & Medical device inventory level & 10.2 & Stock medical device delivered quantity & \\
\hline 5.3 & Consumable inventory level & 10.3 & Stock consumable delivered quantity & \\
\hline 8.1 & \# Stock out order lines & 10 & $\begin{array}{l}\text { Total stock delivered quantity } \\
\text { Rouwenhorst et al., 2000) }\end{array}$ & \multirow[t]{2}{*}{ Manunen (2000; } \\
\hline 8.2 & \# Direct delivery out order lines & 11 & Total direct delivered quantity & \\
\hline 14 & Total operating costs & 3.1 & $\begin{array}{l}\text { WH Area } \\
\text { Gu et al., 2010; } \\
\text { Rao and Rao, 1998) } \\
\text { \# Stock SKUs }\end{array}$ & De Koster et al. (2007; \\
\hline \multirow[t]{6}{*}{13} & \multirow[t]{6}{*}{ Total personnel costs } & 10 & $\begin{array}{l}\text { Total stock delivered quantity } \\
\text { Lam et al., 2011; } \\
\text { Weisner and Deuse, 2014) }\end{array}$ & \multirow[t]{2}{*}{ De Koster et al. (2007; } \\
\hline & & 11 & Total direct delivered quantity & \\
\hline & & 4 & Total \# in order lines & \multirow[t]{4}{*}{ Themido et al. (2000) } \\
\hline & & 8 & Total \# out order lines & \\
\hline & & 4.1 & \# Stock in order lines & \\
\hline & & 8.1 & \# Stock out order lines & \\
\hline \multirow[t]{2}{*}{$13+14$} & \multirow[t]{2}{*}{$\begin{array}{l}\text { (Total personnel costs }+ \\
\text { total operating Costs) }\end{array}$} & 9 & Total delivered quantity & \multirow[t]{2}{*}{ Teo and Shu (2004) } \\
\hline & & 10 & Total stock delivered quantity & \\
\hline \multirow[t]{7}{*}{2} & \multirow[t]{7}{*}{ Total \# of Employees } & 9 & $\begin{array}{l}\text { Total delivered quantity } \\
\text { Lam et al., 2011; } \\
\text { Weisner and Deuse 2014) }\end{array}$ & \multirow[t]{7}{*}{ De Koster et al. (2007; } \\
\hline & & 10 & $\begin{array}{l}\text { Weisner and Deuse, 2014) } \\
\text { Total stock delivered quantity }\end{array}$ & \\
\hline & & 4 & Total \# in order lines & \\
\hline & & 8 & Total \# out order lines & \\
\hline & & 4.1 & \# Stock in order lines & \\
\hline & & 8.1 & \# Stock out order lines & \\
\hline & & 8.2 & \# Direct delivery out order lines & \\
\hline
\end{tabular}




\begin{tabular}{|c|c|c|c|c|c|c|c|c|}
\hline Variable/sub-variable & Mean & Std. Dev & $\mathrm{Q}_{1}$ & $\mathrm{Q}_{2}$ & $\mathrm{Q}_{3}$ & $\mathrm{Q}_{4}$ & Min & $\operatorname{Max}$ \\
\hline $1 \quad$ WH Area $\left[\mathrm{m}^{2}\right]$ & 881 & 1,290 & 259 & 504 & 1,036 & 9,065 & 50 & 9,065 \\
\hline Total \# of Employees [FTE] & 10.5 & 16.2 & 4.5 & 7.1 & 10.9 & 128.7 & 0.2 & 128.7 \\
\hline 3 Total \# of SKUs [items] & 4,768 & 5,100 & 1,345 & 2,809 & 7,288 & 29,284 & 38 & 29,284 \\
\hline $\begin{array}{l}\text { Total stock delivered } \\
\text { quantity [units] }\end{array}$ & $11,233,645$ & $18,026,946$ & $2,766,254$ & $5,709,975$ & $13,599,571$ & $133,316,582$ & 0 & $133,316,582$ \\
\hline $\begin{array}{l}11 \text { Total direct } \\
\text { delivered quantity [units] }\end{array}$ & $1,048,215$ & $2,975,000$ & 21,272 & 289,471 & 747,674 & $22,081,882$ & 0 & $22,081,882$ \\
\hline $\begin{array}{l}\text { Total consignment stock } \\
\text { delivered quantity [units] }\end{array}$ & 6,747 & 33,811 & 0 & 0 & 1,351 & 245,081 & 0 & 245,081 \\
\hline 5.1 Drug inventory level [units] & $1,821,388$ & $12,112,845$ & 41,355 & 224,852 & 506,264 & $99,432,242$ & 0 & $99,432,242$ \\
\hline 5.3 Consumable & 762,384 & $1,381,889$ & 6,679 & 323,265 & $1,025,195$ & $9,465,770$ & 0 & $9,465,770$ \\
\hline inventory level [units] & 561,536 & $1,115,249$ & 0 & 14,951 & 844,985 & $7,597,494$ & 0 & $7,597,494$ \\
\hline 8.1 \# Stock out order lines [lines] & 113,660 & 159,327 & 20,904 & 79,144 & 143,095 & $1,043,926$ & 0 & $1,043,926$ \\
\hline $\begin{array}{l}8.2 \text { \# Direct delivery out } \\
\text { order lines [lines] }\end{array}$ & 6,695 & 11,198 & 520 & 2,652 & 7,540 & 64,237 & 0 & 64,237 \\
\hline
\end{tabular}

\section{Step 4: Collecting Quantitative Data and Building} the Dataset

The relationships listed in Table 2 are empirical in nature, so they require quantitative data in order to be analyzed in specific logistics contexts. Data collection was performed by means of a questionnaire sent to each warehouse manager about the pieces of information necessary to define the numerical values of the investigated variables.

A dataset was then built. Table 3 presents the mean, the standard deviation, the quartiles $\left(\mathrm{Q}_{1}, \mathrm{Q}_{2}, \mathrm{Q}_{3}\right.$ and $\mathrm{Q}_{4}$ ) and the minimum and maximum values of those variables and sub-variables out of the ones reported in Table 1 and 2 representing the main warehouse operational aspects. The numerical values show that the analyzed warehouses are characterized by heterogeneous volumes of products and many of the measured variables are affected by a high degree of variability. This situation is quite common in a fragmented HC logistics system like the one at issue involving a relevant number of warehouses of very different sizes and with heterogeneous customers. Furthermore, the zero values in Table 3 are associated with those warehouses that do not manage the product category or the delivery method the variable refers to.

\section{Step 5: Statistical Analysis}

The approach used in this step was inspired by statistical analyses performed in other fields such as for instance the work by De Marco et al. (2012). As a first step, each of the relationships in Table 2 was analyzed to understand the expected behavior of the dependent variable. In most of these relationships the dependent variable was predicted to increase with the independent variables. Then, linear regression analysis was carried out for each studied relationship (Montgomery and Runger, 2003; Tabachnick and Fidell, 2001) by means of the software tool Minitab ${ }^{\circledR} 16$ by Minitab Inc. In order to be able to compare the results, those variable values constituting outlier observations were removed with the help of the dedicated Minitab functionality. Given IQR the interquartile range $\left(\mathrm{Q}_{3}-\mathrm{Q}_{1}\right)$, Minitab identifies as an outlier any variable value that is outside the interval $\mathrm{IQR} \pm 1.5 \mathrm{IQR}$. This task also allowed to exclude the observations associated with those warehouses not managing the specific kind of product at issue (e.g., consignment stock products, drugs, medical devices, consumable products, etc.) and thus having a value equal to 0 for the variables under consideration. After outlier removal, the total number of available observations was between 72 and 75 depending on the relationship investigated. For those relationships involving more than one independent variable multicollinearity among predictors was explored by calculating the Variance Inflation Factor (VIF) (O'Brien 2007). Variables with VIF greater than 5 were removed from the associated regression model (Tabachnick and Fidell, 2001). Some tests on residuals were carried out with the aim of validating the consistency of the regression models. The normal distribution of residuals, as well as the absence of systematic errors, trends, time series and periodicity in the residuals out of the regressions were checked (Tabachnick and Fidell, 2001).

\section{Results}

This section discusses step 6 of the approach. The statistical analysis outlined in the previous section was applied to all the relationships involving variables and sub-variables presented in Table 2. Table 4 shows the results of selected regression analyses and namely those ones that provide relevant insights for the implementation of warehouse centralization policies. As a summary of the obtained statistical outputs, the pvalue, $R^{2}$, adjusted $R^{2}$ and the values of VIF in the final 
regression model are shown. In case of multiple independent variables, their relationship with the associated dependent variable was tested both collectively and individually. All the relationships in Table 4 were found to be positive. Since the goal of this first application of the approach is just finding management commonalities between the warehouses and not the investigation of detailed quantitative aspects, the numerical values of the coefficients are not relevant to the analysis and as such not reported in Table 4. According to statistical literature, p-values less than or equal to $5 \%$ demonstrate the existence of significant relationships between dependent and independent variables (Montgomery and Runger, 2003; Tabachnick and Fidell, 2001).

The most important findings provided by Table 4 are now discussed. There is a positive dependence of the stock level (variable 5) on the average quantity of products delivered from a warehouse to the points of use during one year (variable 10). Such relationship exists not only when total values, including drugs, medical devices and consumable products, are considered but also for each of these three product categories separately. This result proves that the majority of the HC institutions at issue perform an accurate inventory management for all the items regardless of their economic value and strategic importance. Such a common practice is stimulated by the limited economic budgets available in these last few years due to the general economic situation and constitutes an essential element in order to agree on effective stock levels serving multiple organizations from a central warehouse.

The average annual quantities of stock drugs (subvariable 10.1), medical devices (sub-variable 10.2) and consumable products (sub-variable 10.3) delivered to the points of use are all significant determinants of the annual average number of outgoing order lines of stock products (sub-variable 8.1). Thus, in most of the studied warehouses the more the units delivered the more the associated lines, meaning that the $\mathrm{HC}$ organizations usually request few units of product per order line. This demand fragmentation is due to two main reasons. First, the operational conditions of the HC context, largely affected by uncertainty, lead to frequent orders of small quantities of products. Second, in the current decentralized configuration the studied warehouses are located very close to hospitals and clinics, if not inside the same facility, so it is very easy and quick to order and directly get products from them. The demand fragmentation, together with the possibility of easily accessing stocks, might be obstacles to the implementation of warehouse centralization initiatives.

The average quantities of both stock (variable 10) and direct delivery products (variable 11) that are shipped from the warehouse in one year are significant factors influencing the cost of the personnel (variable 13). This result is partially in contrast with the expectations. Stock products imply a heavier workload than direct delivery ones because they need to be received, inspected, stored, picked and prepared to be delivered to the points of use. On the contrary direct delivery products are just received, inspected and delivered to the points of use without any additional operations. As a consequence, the quantity of direct delivery products shipped over one year should be less relevant than the delivered quantity of stock products in determining the personnel requirements and so the related costs. Nevertheless, the two variables were found to be equally significant for the analyzed warehouses. This reveals that most of the focus HC institutions are characterized by a limited efficiency in human resource allocation, which is another obstacle to the adoption of warehouse centralization policies. In fact, provided that the studied organizations already manage inventories based on the actual product consumption, the main source of savings when centralizing warehouses comes from the decreased need for human resources. If the number of employees in the decentralized configuration tends to be high, it will be difficult to perform such a reduction. The scarce efficiency in human resource allocation is also confirmed by the weak relationship between the total cost of personnel (variable 13) and the annual number of incoming (sub-variable 4.1) and outgoing (sub-variable 8.1) order lines of stock products.

There is no relationship between the number of stock product SKUs (sub-variable 3.1) and the average value of the associated quantity of units delivered over one year (variable 10). Such outcome means that in the analyzed warehouses there is a relevant portion of the SKUs whose demand is not significant in amount and probably they are not often requested by points of use. SKUs with low annual demand volume might be managed as direct delivery products in a centralized warehouse.

The last relationship in Table 4 further confirms a not optimal use of human resources by the warehouses. The variable \# Stock OUT Order Lines (sub-variable 8.1) should be the most significant predictor is determining the value of the variable Total \# of Employees (variable 2 ) and not the number of incoming order lines of stock products (sub-variable 4.1) and the number of outgoing order lines of direct delivery products (sub-variable 8.2) as resulted from the statistical analysis. In fact, the studied warehouses rely on traditional storage racks where entire unit loads are stocked and thus the workload associated with incoming products is reduced compared to the workload associated with picking and packaging single outgoing items. Similarly, direct delivery products are just received, inspected and delivered to the points of use without any additional operations that are instead required for outgoing stock products. 


\begin{tabular}{|c|c|c|c|c|c|c|}
\hline & & & & Statistic & atput & \\
\hline & & & & & $\mathrm{R}^{2} /$ & \\
\hline Dep & endent variable & Indepe & dent variable & p-value & Adjusted $\mathrm{R}^{2}$ & VIF \\
\hline 1 & WH area $\left[\mathrm{m}^{2}\right]$ & 5 & Total inventory level [units] & 0.013 & $79.53 \%$ & - \\
\hline 5 & Total inventory level [units] & 10 & Total stock delivered quantity [units] & 0.000 & $81.86 \%$ & - \\
\hline 5.1 & Drug inventory level [units] & 10.1 & Stock drug delivered quantity [units] & 0.000 & $79.75 \%$ & - \\
\hline 5.2 & Medical device inventory level [units] & 10.2 & Stock medical device delivered quantity [units] & 0.000 & $98.46 \%$ & - \\
\hline 5.3 & Consumable inventory level [units] & 10.3 & Stock consumable delivered quantity [units] & 0.000 & $96.90 \%$ & - \\
\hline 8.1 & \# Stock out order lines [lines] & 10.1 & Stock drug delivered quantity [units] & 0.005 & $75.00 \%$ & 1.496 \\
\hline & & 10.2 & Stock medical device delivered quantity [units] & 0.004 & & 3.479 \\
\hline & & 10.3 & Stock consumable delivered quantity [units] & 0.004 & & 2.960 \\
\hline 14 & Total operating costs $[€]$ & 1 & WH area $\left[\mathrm{m}^{2}\right]$ & 0.024 & $92.63 \%$ & - \\
\hline 13 & Total personnel costs $[€]$ & 10 & Total stock delivered quantity [units] & 0.000 & $80.60 \%$ & 1.087 \\
\hline & & 11 & Total direct delivered quantity [units] & 0.000 & & 1.087 \\
\hline 13 & Total personnel costs $[€]$ & 4.1 & \# Stock in order lines [lines] & 0.089 & $65.40 \%$ & 1.798 \\
\hline & & 8.1 & \# Stock out order lines [lines] & 0.000 & & 1.798 \\
\hline 10 & Total stock delivered quantity [units] & 3.1 & \# Stock SKUs [items] & 0.001 & $26.39 \%$ & - \\
\hline 1 & WH area $\left[\mathrm{m}^{2}\right]$ & 3 & Total \# SKUs [items] & 0.000 & $28.20 \%$ & - \\
\hline 8.2 & \# Direct delivery out order lines [lines] & 11 & Total direct delivered quantity [units] & 0.159 & $73.40 \%$ & - \\
\hline 2 & Total \# of employees [FTE] & 4.1 & \# Stock in order lines [lines] & 0.002 & $79.10 \%$ & 4.651 \\
\hline & & 8.1 & \# Stock out order lines [lines] & 0.111 & & 3.593 \\
\hline & & 8.2 & \# Direct delivery out order lines [lines] & 0.002 & & 2.381 \\
\hline
\end{tabular}

Overall, the warehouses revealed a good degree of commonality and correctness in their management practices. However, the outcomes highlighted three critical aspects: A limited efficiency in human resource allocation, a high fragmentation of stock product demand and a relevant number of stock product SKUs with low annual demand in terms of quantity. The material managers in the working group validated the results of the application of the approach and agreed on the need to carefully consider the above mentioned issues when undertaking warehouse centralization initiatives.

\section{Discussion}

This approach gives a first understanding of the behavior of many different individual institutions by identifying management commonalities that can support warehouse centralization strategies and criticalities that could hinder them. Since it is based on a significant number of different variables and relationships among them and on all the product types in a $\mathrm{HC}$ warehouse, it contributes to overcome the traditional approach to HC SCs limited to the analysis of single aspects of these systems (Bhakoo et al., 2012; Rich and Piercy, 2013). Also, it provides an evaluation of the ex-ante conditions of the organizations involved in centralization initiatives, while several existing pieces of research discuss expost benefits (Lega et al., 2013). Furthermore, being based on a quantitative statistical tool, it avoids bias characterizing subjective qualitative assessments.
From an academic perspective, the presented approach can stimulate the development of research aimed at providing a comprehensive understanding of the functioning and the performance of HC SCs. Also, it fosters the enlargement of the stream of research about centralized supply networks. From a practical perspective, it offers a structured methodology to increase material managers' knowledge and awareness about the factors enabling centralized warehouse and logistics strategies.

However, the developed approach suffers from some limitations. First, performing a preliminary analysis at quite a general level, it needs to be followed by further deeper investigations about the specific behavior of each single warehouse in order to assess whether it is actually candidate for a future centralization regime. Second, it is based on a strong commitment of the involved $\mathrm{HC}$ institutions and on a great amount of data in order to enable sound statistical analyses: These conditions might not exist in certain contexts. Finally, additional validation is required to fully demonstrate the effectiveness of the methodology.

Therefore, future research will aim to validate the approach in different $\mathrm{HC}$ systems and expand it from the analysis of warehouses and their connections with the points of use to the study of the links with their external SC partners such as producers, wholesalers and distributors. Additionally, outsourcing of the operations carried out in centralized warehouses will be addressed as well as alternative ways of inventory pooling such as transshipment. 


\section{Conclusion}

Centralized logistics leads different HC organizational units to standardize products and procedures, with significant economies of scale and scope. The scientific community has just started addressing centralized $\mathrm{HC}$ SCs by studying their operational and economic implications. This work contributes to enrich such a research stream by offering a preliminary approach to assess the degree of commonalities between material management practices adopted by different $\mathrm{HC}$ institutions before the implementation of a centralized warehouse model. The results of its first application allowed highlighting the main criticalities that the studied organizations should tackle in order to enable successful centralization processes.

\section{Acknowledgment}

The authors would like to thank the anonymous healthcare institutions that participated in the development and first test of the proposed approach.

\section{Funding Information}

This research was done by self-financing.

\section{Author Contributions}

The authors contributed to the paper equally.

\section{Ethics}

This article is original and contains unpublished material. The corresponding author confirms that all of the other authors have read and approved the manuscript and no ethical issues involved.

\section{References}

Alptekinoğlu, A., A. Banerjee, A. Paul and N. Jain, 2012. Inventory pooling to deliver differentiated service. Manufactur. Service Operations Manag. DOI: $10.1287 / \mathrm{msom} .1120 .0399$

Alrawabdeh, W., A. Salloum and F. Shrafat, 2015. Factors affecting the implementation of the national programme for information technology in the national health services: The case of Lorenzo in the North, Midlands and East of England region. Am. J. Applied Sci., 12: 20-30.

DOI: 10.3844/ajassp.2015.20.30

Aronsson, H., M. Abrahamsson and K. Spens, 2011. Developing lean and agile health care supply chains. Supply Chain Manage. Int. J., 16: 176-183. DOI: $10.1108 / 13598541111127164$
Azzi, A., A. Persona, F. Sgarbossa and M. Bonin, 2013. Drug inventory management and distribution: Outsourcing logistics to third-party providers. Strategic Outsourc. Int. J., 6: 48-64. DOI: $10.1108 / 17538291311316063$

Battini, D., M. Faccio, A. Persona and F. Sgarbossa, 2013. Modelling the growing process of integrated healthcare supply networks. Int. J. Syst. Dyn. Applic., 2: 1-13. DOI: 10.4018/ijsda.2013010101

Bendavid, Y. and H. Boeck, 2011. Using RFID to improve hospital supply chain management for high value and consignment items. Proc. Comput. Sci., 5: 849-856. DOI: 10.1016/j.procs.2011.07.117

Bhakoo, V., P. Singh and A. Sohal, 2012. Collaborative management of inventory in Australian hospital supply chains: Practices and issues. Supply Chain Manag. Int. J., 17: 217-230. DOI: $10.1108 / 13598541211212933$

Böhme, T., S.J. Williams, P. Childerhouse, E. Deakins and D. Towill, 2013. Methodology challenges associated with benchmarking healthcare supply chains. Product. Plann. Control: Manage Operat., 24: 1002-1014. DOI: $10.1080 / 09537287.2012 .666918$

Brewer, A.M., K.J. Button and D.A. Hensher, 2008. Handbook of Logistics and Supply-Chain Management. 3rd Edn., Pergamon, Amsterdam, New York.

Brunetta, F., L. Giustiniano and L. Marchegiani, 2014. Caring more by doing less? An enquiry about the impacts of outsourcing on patient care. Am. J. Applied Sci., 11: 273-279. DOI: 10.3844 /ajassp.2014.273.279

Çelebi, D., 2015. Inventory control in a centralized distribution network using genetic algorithms: A case study. Comput. Ind. Eng., 87: 532-539. DOI: 10.1016/j.cie.2015.05.035

Damelio, R., 2011. The Basics of Process Mapping. 2nd Edn., CRC Press, ISBN-10: 1439863180, pp: 183.

De Koster, R., T. Le-Duc and K.J. Roodbergen, 2007. Design and control of warehouse order picking: A literature review. Eur. J. Operat. Res., 182: 481-501. DOI: 10.1016/j.ejor.2006.07.009

De Marco, A., G. Mangano, A.C. Cagliano and S. Grimaldi, 2012. Public Financing into buildoperate-transfer hospital projects in Italy. J. Constr. Eng. Manage., 138: 1294-1302. DOI: $10.1061 /(A S C E) C O .1943-7862.0000545$

De Vries, J., 2011. The shaping of inventory systems in health services: A stakeholder analysis. Int. J. Prod. Econ., 133: 60-69. DOI: 10.1016/j.ijpe.2009.10.029

Eppen, G.D., 1979. Effects of centralization on expected costs in amulti-location newsboy problem. Manage. Sci., 25: 498-501. DOI: 10.1287/mnsc.25.5.498 
Faber, N., M.B.M. De Koster and A. Smidts, 2013. Organizing Warehouse Management. Int. J. Operat. Prod. Manag., 33: 1230-1256.

DOI: 10.1108/IJOPM-12-2011-0471

Ferretti, M., F. Favalli and A. Zangrandi, 2014. Impact of a logistic improvement in an hospital pharmacy: Effects on the economics of a healthcare organization. Int. J. Eng. Sci. Technol., 6: 85-95. DOI: $10.4314 /$ ijest.v6i3.7S

Frazelle, E.H., 2002. Supply Chain Strategy: The Logistics of Supply Chain Management. 1st Edn., McGraw-Hill, New York, ISBN-10: 0071375996, pp: 357.

Gu, J., M. Goetschalckx and L.F. McGinnis, 2010. Research on warehouse design and performance evaluation: A comprehensive review. Eur. J. Operat. Res., 203: 539-549. DOI: 10.1016/j.ejor.2009.07.031

Karsten, F. and R.J.I. Basten, 2014. Pooling of spare parts between multiple users: How to share the benefits? Eur. J. Operat. Res., 233: 94-104.

DOI: 10.1016/j.ejor.2013.08.029

Lam, C.H.Y., K.L. Choy and S.H. Chung, 2011. A decision support system to facilitate warehouse order fulfillment in cross-border supply chain. J. Manuf. Technol. Manage., 22: 972-983. DOI: $10.1108 / 17410381111177430$

Lee, D.J. and I.J. Jeong, 2009. Regression approximation for a partially centralized inventory system considering transportation costs. Comput. Ind. Eng., 56: 1169-1176. DOI: 10.1016/j.cie.2008.06.005

Lega, F., M. Marsilio and S. Villa, 2013. An evaluation framework for measuring supply chain performance in the public healthcare sector: Evidence from the Italian NHS. Prod. Plan. Control, 24: 931-947. DOI: $10.1080 / 09537287.2012 .666906$

Manunen, O., 2000. An activity-based costing model for logistics operations of manufacturers and wholesalers. Int. J. Logist. Res. Applic., 3: 53-65. DOI: $10.1080 / 13675560050006673$

Marquès, G., C. Thierryb, J. Lamothea and D. Gourca, 2010. A review of Vendor Managed Inventory (VMI): From concept to processes. Prod. Plan. Control, 21: 547-561. DOI: 10.1080/09537287.2010.488937

Montgomery, D.C. and G.C. Runger, 2003. Applied Statistics and Probability for Engineers. 3rd Edn., John Wiley and Sons, New York, ISBN-10: 0471381810, pp: 706.

Nicholson, L., A.J. Vakharia and S.S. Erenguc, 2004. Outsourcing inventory management decisions in healthcare: Models and application. Eur. J. Operat. Res., 154: 271-290.

DOI: $10.1016 / \mathrm{S} 0377-2217(02) 00700-2$

O'Brien, R.M., 2007. A caution regarding rules of thumb for variance inflation factors. Qual. Quant., 41: 673-690. DOI: 10.1007/s11135-006-9018-6
Pan, Z.X. and S. Pokharel, 2007. Logistics in hospitals: A case study of some Singapore hospitals. Leadersh. Health Serv., 20: 195-207. DOI: $10.1108 / 17511870710764041$

Pedersen, S.G., F. Zachariassen and J.S. Arlbjørn, 2012. Centralisation Vs decentralization of warehousing. J. Small Bus. Enterp. Dev., 19: 352-369. DOI: $10.1108 / 14626001211223946$

Rao, A.K. and M.R. Rao, 1998.Solution procedures for sizing of warehouses. Eur. J. Operat. Res., 108: 16-25. DOI: 10.1016/S0377-2217(97)00159-8

Rich, N. and N. Piercy, 2013. Losing patients: A systems view on healthcare improvement. Prod. Plan. Control, 24: 962-975.

DOI: $10.1080 / 09537287.2012 .666911$

Rouwenhorst, B., B. Reuter, V. Stockrahm, G.J. van Houtum and R.J. Mantel et al., 2000. Warehouse design and control: Framework and literature review. Eur. J. Operat. Res., 122: 515-533. DOI: 10.1016/S0377-2217(99)00020-X

Scheller, E.S. and L.R. Smeltzer, 2006. Strategic Management of the Health Care Supply Chain. 1st Edn., Wiley, San Francisco, ISBN-10: 0787980390, pp: 305.

Schmitt, A.J., S.A. Sun, L.V. Snyder and Z.J.M. Shen, 2015. Centralization versus decentralization: Risk pooling, risk diversification and supply chain disruptions. Omega, 52: 201-212.

DOI: $10.1016 /$ j.omega.2014.06.002

Silver, E.A., D.F. Pyke and R. Peterson, 1998. Inventory Management and Production Planning and Scheduling. 3rd Edn., John Wiley and Sons, New York, ISBN-10: 0471119474, pp: 784.

Su, S.I.I., B. Gammelgaard and S.L. Yang, 2011. Logistics innovation process revisited: Insights from a hospital case study. Int. J. Phys. Distrib. Logist. Manag., 41: 577-600. DOI: $10.1108 / 09600031111147826$

SCC, 2012. Supply-Chain operations reference-model. Version 11.0. Supply-Chain Council, Pittsburgh, PA.

Suresh, D. and P. Alli, 2012. An overview of research issues in the modern healthcare monitoring system design using wireless body area network. Am. J. Applied Sci., 9: 54-59. DOI: 10.3844 /ajassp.2012.54.59

Tabachnick, B.G. and L.S. Fidell, 2001. Using Multivariate Statistics. 4th Edn., Harper Collins, New York, ISBN-10: 0321056779, pp: 966.

Teo, C.P.and J. Shu, 2004. Warehouse-retailer network design problem. Operat. Res., 52: 396-408. DOI: $10.1287 /$ opre. 1030.0096

Themido, I., A. Arantes, C. Femandes and A.P. Guedes, 2000. Logistic costs case study-an ABC approach. J. Operat. Res. Soc., 51: 1148-1157. DOI: $10.2307 / 253927$ 
Wang, W. and S. Yue, 2015. An inventory pooling model for spare units of critical systems that serve multi-companies. Transp. Res. Part E, 76: 34-44. DOI: $10.1016 /$ j.tre.2015.02.002

Wanke, P.F. and E. Saliby, 2009. Consolidation effects: Whether and how inventories should be pooled. Transp. Res. Part E, 45: 678-692. DOI: $10.1016 /$ j.tre.2009.01.006

Weisner, K. and J. Deuse, 2014. Assessment methodology to design an ergonomic and sustainable order picking system using motion capturing systems. Proc. CIRP, 17: 422-427.

DOI: 10.1016/j.procir.2014.01.046
Wong, H., D. Van Oudheusden and D. Cattrysse, 2007. Cost allocation in spare parts inventory pooling. Transp. Res. Part E, 43: 370-386. DOI: $10.1016 /$ j.tre.2006.01.001

Wu, D., M.D. Rossetti and J.E. Tepper, 2015. Possibility of inventory pooling in china's public hospital and appraisal about its performance. Applied Math. Model., 39: 7277-7290.

DOI: 10.1016/j.apm.2015.02.042 